\title{
The Application of Hypnosis in College Psychological Counseling
}

\author{
Nan $\mathbf{L i}^{1}$, Shulian $\mathbf{L i}^{2^{*}}$ \\ ${ }^{1}$ Boda College of Jilin Normal University, Siping City, Jilin Province, 136000, China. \\ ${ }^{2}$ Jilin Normal University, Siping City, Jilin Province, 136000, China. \\ E-mail: 65626493@qq.com
}

\begin{abstract}
With the continuous development of society, more and more people have begun to pay attention to the health problems of human psychology. In the past, people's psychological problems were not valued for some reason, and there was no proper way to solve the problems. Especially for some college students, their psychological problems are easily overlooked. Most people think that college students only need to learn every day without worrying about other things and will not be troubled by psychological problems. But this is not the case. College students will be troubled by study, love affair, and worry about their future work and life. Therefore, it is necessary to provide psychological counseling services in colleges and universities. In response to these problems, this article will focus on the specific application of hypnosis in college psychological counseling.
\end{abstract}

Keywords: Hypnosis College Psychological Counseling

\section{A brief overview of hypnosis}

As early as in ancient Rome, hypnosis had already appeared. At that time, hypnosis was mainly applied to the treatment of certain diseases. During the treatment process, the pain caused by the disease was reduced as much as possible. In addition, there are also very early records in the religious history of the West, which are mainly used for the psychological comfort and baptism of believers. In the modern West, hypnosis has been officially applied to medical treatment, and most of them are used to treat mental diseases. The medical value of hypnosis has been studied by some experts and scholars, and different schools have different views. In essence, hypnosis means that the hypnotized person himself brings his consciousness to a third perspective through his psychological hint to himself, so that the hypnotized person is in a semi-dream and awake state, that is, completely in a subconscious state. ${ }^{[1]}$ When the patient enters this state, the hypnotist can take some professional technical methods to achieve a certain therapeutic effect. Hypnosis is very effective for the treatment of mental illness, and it is particularly valued in Western countries. Many famous foreign universities have set up hypnosis treatment specialties, which shows the complexity of the use of hypnosis. There are many psychological clinics in China that can perform hypnosis therapy, and there are many books on hypnosis in the market; not only that, hypnosis techniques are widely applicable, such as philosophy and psychology. However, our country lags behind some western countries in the field of hypnosis. There are few universities offering psychology. Most of the books on the market also come from abroad. Therefore, hypnosis has great room for development in China. ${ }^{[2]}$

\section{Hypnosis promotes student psychological counseling}

Many years ago, many people thought of hypnosis as soon as they heard the word hypnosis, and some even mistakenly believed that hypnosis was a way to confuse people. Some film and television dramas will also describe various hypnosis, but most of those hypnosis are not consistent with the actual situation. Many college students are exposed to hypnosis from movies and TV shows, and most of them cannot correctly recognize hypnosis. Therefore, if

Copyright (C) 2020 Shuhua Li et al. .

doi: 10.18282/le.v9i5.1259

This is an open-access article distributed under the terms of the Creative Commons Attribution Non-Commercial License

(http://creativecommons.org/licenses/by-nc/4.0/), which permits unrestricted non-commercial use, distribution, and reproduction in any medium, provided the original work is properly cited. 
you want to make hypnosis popular among college students, you must let students really understand this phenomenon, so as to erase the unscientific impression of unreasonable hypnosis in their hearts; and also make them understand hypnosis The purpose is to consciously go to college psychological counseling when you have a mental need, so that the psychology teacher can help students solve psychological confusion, so as to avoid mental illness affecting physical health. Therefore, psychological staff in colleges and universities can expose students to hypnosis by giving lectures or publicly holding psychological salons. When students are exposed to this treatment, they will naturally dispel their concerns. The general acceptance ability of college students is still very strong, and in the specific treatment process, it also has a great advantage in the overall grasp of hypnosis, and it is easy to achieve the effect of deep hypnosis.

\section{Conduct group counseling and counseling}

Hypnosis can be used in group psychological counseling and counseling. Group psychological counseling refers to psychological counseling services in which multiple people provide counseling at the same time and use the group's situational model to provide patients with certain psychological assistance. For the group of college students, it is different from the external psychological counseling service, because the environment of the college students is similar to the previous life experience, but for the people in the society, their life experience is different, so They cannot perform group psychological counseling services; the use of group psychological counseling services on university campuses can effectively improve the efficiency of psychological work. When hypnosis is applied in a group, it can be more conducive to students entering the subconscious, and the ability to self-acceptance will be higher. Because when most people perform psychological hypnosis together, many people will develop a herd consciousness and comparative consciousness, which makes it easier to achieve the desired effect of hypnosis. When performing group psychological hypnosis services, psychological staff must ensure that the on-site environment is very quiet and comfortable, because in a comfortable environment, students can relax, even for indoor lighting and indoor decoration color matching are required The temperature of the indoor air conditioner should also be appropriate.[3]For some classmates, their inner hearts are relatively fragile, and they have a special experience. When conducting group hypnosis, the psychological counseling teacher must always pay attention to the emotional changes of the students and provide comfort when appropriate. The number of people should not be too large during group psychological hypnosis. Try to control it within 15 people. Once the number is increased, it will affect the expression of normal emotions and ultimately fail to achieve the purpose of psychological treatment. Of course, in order to better achieve the purpose of the experiment, before the formal hypnosis, students can properly understand each other and understand each other, and sometimes students can comfort each other. Although it is a group psychological consultation, the psychological counseling teacher must take care of each student's feelings, which places high demands on the teacher's ability. Due to the difference in living environment and life experience of each student, the focus of each person's suggestive content and suggestive content is different. Hypnotic sensibility determines the entire hypnotic effect. Before the test, the psychological counselor can divide the students into two groups with higher susceptibility and lower susceptibility in advance, and use different hypnotic methods for different groups; at the same time, in addition to the psychological counselor's soft and gentle tone for language stimulation during hypnosis In addition, you should put some long, soothing songs, or let the students relax in advance. Hypnosis itself plays a very small role in solving the problems of students' hearts. It is more that students can face themselves through this hypnosis, face their deficiencies and problems, and then communicate with teachers and classmates through sharing. At this time, the hypnosis teacher should instill the correct mentality to the students in the correct way, so that the students can completely solve the psychological doubts and confusion.[4]

\section{The role of hypnosis in psychological counseling}

\subsection{Eliminate bad mentality and build self-confidence}

Everyone has more or less psychological problems, as do college students. In particular, students from some small places entered the university through the college entrance examination. They used to rank very high in the class, but the university has students from all over the world, and they no longer have the same influence in the class as before. At this time, these students will form a psychological gap and cause some psychological problems. If these psychological problems cannot be guided in time, it will affect the students' academic performance and even their future lives. In addition, there are also some students who have a strong sense of inferiority because of the trauma of their hearts and 
the influence of their academic background. Students with a strong sense of inferiority often use some negative and negative words about themselves: I can't, I'm worse than others. Through these negative emotions, the problems of the students can be analyzed, so the psychological counseling teacher should use hypnosis skills to let the students face their inner fears under the hypnotic state, help the students to establish positive cues of themselves, and finally achieve the elimination of negative emotions. purpose. The hypnotist understands the inferiority of the patient in advance. For example, some people usually have stuttering problems. They often have a sense of inferiority on certain occasions, so the hypnotist understands its characteristics in advance and combines it with hypnosis. In that particular scene, it is helpful for students to enter a state of deep hypnosis, which is convenient for hypnotists to start treatment. When some students enter a state of deep hypnosis, then they will repeat some pictures that will cause them pain over and over again. At this time, the hypnotist needs to create a way for them to overcome difficulties through the output of speech The scene, or to create a happy scene for them to overcome difficulties. This can slowly eliminate some people's mental illness. Of course, not all students rely on hypnosis to solve psychological problems. Some also need emotional catharsis to treat their deep inner pain through emotional catharsis.

\subsection{Using hypnosis to treat Internet addiction}

The Internet is everywhere nowadays, and the temptation of the Internet is also increasing. Many students are studying hard in junior high school. At that time, their parents restricted the time to play mobile phones or online games; however, after the students passed the college entrance examination and entered the university, they were not constrained by their parents for the first time, and they were free to arrange their time. And there is a lot of time in the university that can be arranged independently, but for some students with poor self-control ability, they are very likely to be unable to control themselves for a long time, and Internet addiction will form in the long run, resulting in academic performance. The decline, even do not get a diploma. Now every year, many students are unable to work due to the decline in grades due to long-term playing games in college. Such internet addiction disorder should be stopped. Therefore, it is a good way to use hypnosis to help college students to eliminate Internet addiction. When the student is in a state of hypnosis, the hypnotist can directly imply that the long-term adult is addicted to the harm of the network through language, and can also help tell him how to overcome his own methods and give them some encouragement, thereby making the student less dependent on you.

\subsection{Use hypnosis to fight anxiety}

In fact, this kind of anxiety can be felt by everyone, especially under certain special circumstances. For college students, their anxiety mainly comes from the pressure on the academic test, whether they can find a good job after graduation, etc. In particular, some students are particularly sensitive to the stress of the exam, which is manifested by symptoms such as loss of appetite, insomnia or drowsiness. When the hypnotist guides this situation, he must give the student a whole-body relaxation therapy. Through the language input, the patient can breathe evenly and the muscles of the whole body can be relaxed. When the student enters the state of deep hypnosis, the hypnotist can Create an exam situation, let students enter the exam room, and then let them use the correct relaxation method to complete the exam, and let them feel the state of fast and quick thinking in the process of making questions, so that they like this Kind of feeling. Hypnosis can help students solve anxiety to a great extent.[5]

\section{References}

1. Zhou Aibao, Jiang Yanfei, Yuan Yan, etc. The effect of group hypnosis on test anxiety of senior three students[J]. Chinese Mental Health Journal,2012,(5).363-367.doi:10.3969/j.issn.1000-6729.2012. 05.010.

2. Liu Ying.Using positive psychological cues to promote students' potential development[J].Journal of Dalian Education Institute,2012,(2).72-73.

3. Tong Ping,Wu Chenghong.A preliminary study on the mechanism of psychological counseling for hypnosis facilitation[J].Chinese Journal of Social Medicine,2010,(3).157-158.doi:10.3969/j.issn.1673-5625.2010.03.013.

4. Wu Chenghong, Tai Qiyang. An empirical study of hypnosis in 75 cases[J]. Journal of Yangzhou University (Higher Education Research Edition), 2008, (3).38-41.doi:10.3969/j.issn.1007-8606.2008.03.010.

5. Jiang Lihua. Application Research of Hypnosis in Classroom Training of Psychological Quality of College Students[J]. Journal of Jilin Education College (mid), 2014, (2). 107-108. 